\title{
CINEMA E HISTÓRIA EM ISRAEL: DE UMA HISTÓRIA A OUTRA
}

\author{
FILM AND HISTORY IN ISRAEL: FROM ONE \\ HISTORY TO ANOTHER
}

Sheila Schvarzman*

Resumo: Desde os anos 1980 a história de Israel vem sendo revista por historiadores e cineastas israelenses que tem colocado a nu a ocupação das terras palestinas na constituição do Estado em 1948. Amós Gitai e Eyal Siwan em seus documentários questionam as narrativas e as imagens oficiais construídas pelo sionismo em busca de uma outra história que leve em conta os palestinos.

Palavras-chave: História e Cinema. Novos historiadores Israelenses. Palestina. Israel. Documentário. Eyal Siwan. Amos Gitai.

\begin{abstract}
Since the 1980s Israel's history has been reviewed by historians and Israeli filmmakers who have made bare the occupation of Palestinian lands in the state constitution in 1948. Amos Gitai and Eyal Siwan in his documentaries questioning the official narratives and images constructed by Zionism in search of another story that take into account the Palestinians.
\end{abstract}

Keywords: History and Film. New Israeli historians. Palestine. Israel. Documentary. Eyal Siwan. Amos Gitai.

* Professora no Programa de Mestrado em Comunicação da Universidade Anhembi Morumbi. É autora de Humberto Mauro e as Imagens do Brasil, São Paulo, Edunesp, 2004 entre outros. E-mail: sheila@uol.com.br 
No documentário Jaffa, a Mecânica da Laranja, de 2009, o israelense Eyal Sivan narra a história das laranjas Jaffa, símbolo das conquistas do sionismo e da criação do Estado de Israel a partir de 1948, quando o deserto teria se transformado, na narrativa oficial israelense, em esplêndido e fértil jardim. Entretanto, sustenta - e documenta - o filme, a cidade de Jaffa e seus laranjais já tinham nesse momento pelo menos um século de existência. Desde 1948, a laranja Jaffa, no entanto conhecida internacionalmente por sua qualidade, deixa de ser símbolo da agricultura palestina para tornar-se emblema do sionismo, metáfora da construção do Estado de Israel pela ocupação da Palestina e desapropriação das terras dos árabes.

Trata-se, em suma, de um objeto privilegiado, por meio do qual o filme procura demonstrar, com uso de farta documentação filmada e entrevistas, de que forma a memória histórica pôde ser manipulada e falseada, não apenas para ocultar o tipo de ocupação existente antes da constituição do Estado israelense (quando judeus e árabes coexistiam não só de maneira pacífica como em cooperação), mas também para apropriar-se de seus símbolos definidores.

Como se pode ver, um filme que põe a nu a percepção de que para existir Israel teve que desalojar outro povo. Trata-se de um dado central apresentado pelo documentário e que, no entanto, foi omitido por Israel durante décadas e substituído pela ideia, muito difundida, sobretudo depois da Guerra dos Seis Dias, em 1967, de que os palestinos não existiam como identidade nacional e autônoma.

No entendimento tradicional israelense, os palestinos, sendo árabes como os sírios, libaneses, tunisianos, iraquianos, poderiam ser absorvidos por esses povos em seus territórios. A mudança dessa percepção, calcada na realidade dos conflitos permanentes na região, e no levantamento da documentação histórica sobre a constituição do Estado entre 1947-1949 vem aparecendo não só no cinema de Eyal Sivan e de Amos Gitai, mas também na produção historiográfica produzida desde 1987 por "novos historiadores" israelenses.

No presente artigo gostaria de apontar algumas dessas mudanças na forma de escrever e interpretar a História de Israel, na historiografia produzida desde o final dos anos 1980, e um processo crítico semelhante em alguns trabalhos da obra cinematográfica de cineastas como Eyal Sivan e Amós Gitai.

Mais do que observar a influência do campo historiográfico sobre o artístico, submetendo ou subordinando o cinema, arte e divertimento ao crivo 'sério' da História, me parece mais oportuno, ao contrário, lembrar que o cinema não é e não pode ser visto unicamente como um 'reflexo' da sociedade, fonte onde é possível conhecer aspectos da história, mas é também lugar de instituição de formas dessa mesma história, onde se manifestam inclusive, como no caso de Sivan e Gitai, crítica e reflexão histórica. 
Para romper com a subordinação 'sábia' entre o conhecimento metódico da história e a subjetividade da arte submetida à condição massiva, ideológica, supostamente alienante do cinema, gostaria de trazer à discussão a noção de Historicidade conforme cunhada por François Hartog uma vez que dessa forma se pode pensar essas questões de maneira mais orgânica:

Entendo a noção de historicidade como uma formulação erudita da experiência do tempo que, em troca, modela nossa forma de dizer e viver nosso próprio tempo. Um regime de historicidade abre e circunscreve um espaço de trabalho e de pensamento. Ele dá ritmo à escrita do tempo, representa uma ordem à qual podemos aderir ou, ao contrário (e mais frequentemente), da qual queremos escapar, procurando elaborar outra. ${ }^{1}$

Essa noção permite observar as relações entre a produção de conhecimento de cineastas e historiadores de forma autônoma, ao mesmo tempo em que,

[...] assegura uma compreensão epistêmica das diferenças do saber histórico e sua cultura envolvida. Um regime de historicidade herda, de outro, suas práticas, conceitos, valores, ambições, objetos, e há inter-relações entre eles. A noção também contempla a dimensão cotidiana da cultura histórica que hoje perpassa as produções midiáticas, a arquitetura e o urbanismo, o patrimônio e os museus, as memórias de família e outros mais, ou seja, diferencia protagonistas, procedências e debates. O regime de historicidade, no entanto, não se poupa de indagar compreensões da cultura histórica no senso comum, sem homogeneizá-las. ${ }^{2}$

É portanto dessa perspectiva autônoma e ao mesmo tempo de relação epistêmica que pretendo levantar algumas observações sobre como historiadores e cineastas vêm escrevendo a história de Israel e do conflito israelo-palestino nas duas últimas décadas. O conflito é elemento constitutivo dessa história e suas repercussões incidem sobre a identidade de Israel - multifacetada pela diversidade interna de culturas que a compõem e à qual se acresce a postura em relação à paz e, portanto, à necessidade de reconhecimento do povo palestino. 


\section{UMA NOVA HISTÓRIA?}

Desde o início dos anos 1980, sobretudo depois dos massacres de Sabra e Shatila, no Líbano em 1982, surgiram pesquisadores que vem interrogando a história de Israel de uma nova perspectiva. Dois fatores explicam a emergência de novas visões dessa história. Passados 50 anos, tornou-se possível o acesso à documentação sobre a formação do Estado de Israel, a partir dos anos 1940. A leitura da documentação foi modulada por acontecimentos como a Guerra no Líbano, e a primeira Intifada em 1987, quando se acirraram no país as divisões ideológicas entre o campo nacionalista e o campo da paz. ${ }^{3}$

Ainda que de tendências políticas diversas, mas ligados todos ao campo da paz, esses 'novos historiadores' colocaram em evidência a origem do problema palestino no mesmo momento em que este emerge ao primeiro plano e pede novas soluções - em 15 de novembro de 1988, o Conselho Nacional palestino proclamou o Estado da Palestina e condenou o terrorismo. ${ }^{4}$ Nesse mesmo ano surgiu The Birth of the Palestinian Refugee Problem 1947-1949, de Benny Morris, editado em inglês. ${ }^{5}$

Como mostra Ilan Pappe ${ }^{6}$, foi só nesse momento de aproximação que historiadores israelenses puderam perceber o valor de trabalhos universitários palestinos, até então considerados como pura propaganda. "[...] os pesquisadores israelense tomaram consciência da contradição fundamental entre as ambições nacionais sionistas e sua prática em relação à população palestina". ${ }^{7}$

Para tanto se debruçaram no que definem como mitos intocáveis da história de Israel: a Guerra de Independência e o êxodo palestino. Para Benny Morris autor de The Birth of the Palestinian Refugee Problem, 1947-1949 ou Ilan Pappe ${ }^{8}$ tratava-se de revisitar as origens, observando como o movimento sionista, diante de um povo aniquilado pelos horrores da Shoah, procurou reparar a barbárie através da consolidação de um lugar de proteção. Entretanto, para que esse lugar surgisse, foi preciso desalojar outro povo. Assim, haveria, como questiona Joseph Algazy, um pecado original de Israel? ${ }^{9}$ Não terá Israel, para existir, submetido um povo ao êxodo e à opressão? - é o que se perguntaram. Mais ainda: conforme observam na documentação, não terá sido esse êxodo, em alguns momentos, também uma expulsão?

Esse é o cerne das discussões e das novas descobertas, conforme a apresentação dos historiadores feita por Dominique Vidal ${ }^{10}$ e que, traduzidos apenas em 2008 na França, seguem inéditos no Brasil. Mas eles existem. Existem e indagam o seu passado e sua herança necessariamente beligerante com desconfiança e crítica. Se não há paz, se não há possibilidade de entendimento, algo entre 1947 e 1948, entre a Partilha da Palestina pela ONU e a Declaração e a Guerra de Independência ocorreu e subtraiu de um povo seus direitos. Esses direitos devem ser encarados e, essencial para a paz, eles acreditam, reconhecidos em toda a sua extensão. 


\section{DESCONSTRUINDO A HISTÓRIA}

Essa nova história foi escrita de um ponto de vista e com documentação basicamente israelense: fontes oficiais do governo, do exercito, fontes inglesas e fontes privadas. Benny Morris, por exemplo, teve acesso aos diários particulares de Ben Gurion, que o ajudaram a modular outra história da Guerra de Independência e do êxodo palestino.

A Guerra da Independência foi construída na historiografia tradicional israelense como a batalha heroica de um pequeno e bravo povo praticamente desarmado contra um exército potente, numeroso e bem armado de várias nações árabes, que atacou o país de surpresa no momento em que comemorava a sua independência. Um duelo de David contra Golias. No filme americano A sombra de um gigante, de Melville Shavelson (Cast a Giant Shadow), feito em $1966^{11}$, podemos ter a mais viva expressão dessa visão. Ali a pobreza e a impotência do povo fragilizado saído do Holocausto se transmutava em combatentes aguerridos que, apesar da falta de recursos, e com a ajuda de um experiente militar judeu americano, consegue vencer a batalha.

O filme trata da liberação da estrada que vai de Tel Aviv a Jerusalém, palco de sangrentas batalhas entre israelenses e o exército árabe. Se no filme é a esperteza e a sagacidade de Kirk Douglas (Mickey Marcos) e seus comandados que conseguem formular uma estratégia para abrir caminho e religar o país, segundo os novos historiadores, ao contrário, abrir esse caminho implicou também constrangimento, expulsões e até massacres contra a população palestina.

Ao contrário dessa visão, segundo documentação levantada por Benny Morris sobre a Guerra de Independência, parte dos armamentos israelenses havia sido tomada dos ingleses pela Haganá ${ }^{12}$ quando seus membros participaram em operações conjuntas durante a Segunda Guerra Mundial, e logo depois chegaram também através dos russos. Quanto à fragilidade das forças israelenses, com a prática militar da Haganá e de sua participação no exército inglês, se eram menos numerosos, estavam mais bem treinados, contavam com o apoio político americano e diplomático e militar dos russos. Os árabes, ao contrário, que vinham de várias nações, não tinham treinamento, não sabiam operar o equipamento, que não era novo, e, sobretudo não se entendiam.

O outro mito significativo, decorrente do primeiro, diz respeito ao êxodo voluntário dos palestinos entre 1947-1949. Segundo as fontes oficiais israelenses, 500 mil palestinos teriam deixado suas terras e propriedades, atiçados pelos países árabes que pediam a esses que abandonassem suas terras a fim de não se tornarem alvo na guerra; eles poderiam retornar a suas casas rapidamente, uma vez que os exércitos árabes venceriam o combate e riscariam Israel do mapa. 
Segundo Morris, no entanto, pela documentação levantada 70 mil palestinos saíram voluntariamente.

Simcha Flapan, em seu livro The Birth of Israel. Myths and Realities ${ }^{13}$, observa ainda que entre as terras designadas inicialmente para Israel na partilha da ONU e as terras que Israel tomou durante a guerra, houve um acréscimo de $1 / 3$ sobre o que estava designado aos palestinos.

Impossível não ver nessa leitura que se promove a partir dos anos 1980 os reflexos das posturas políticas de Israel em relação aos palestinos, inclusive no final dos anos 1990 e 2000. Impossível não ver também, ao mesmo tempo, uma busca por 'responsáveis' em relação a um estado de guerra permanente com o qual os adeptos do campo da paz não querem mais conviver, assim como não querem servir o exército em zonas ocupadas, e são até mesmo presos, como Benny Morris, ou passam a viver no exterior, como Ilan Pappe, antigo membro do Partido Comunista, favorável a um estado binacional, e que voluntariamente se exilou na Inglaterra ${ }^{14}$ para não ter que conviver com esse estado de coisas. A derrisão com os territórios ocupados e a falta de interlocução com os próprios palestinos, divididos agora pelo radicalismo do Hamas e seus ataques que ameaçam diretamente a população de cidades centrais como Haifa, entre outras, marcam profundamente esses trabalhos. Não há mais a necessidade ou a ilusão de fronteiras seguras, como se apregoava, que justificaram a ocupação dos territórios da guerra de 1967. A inexistência de segurança não diz mais respeito a fronteiras territoriais.

Nesses trabalhos que inclusive dispensam o testemunho palestino, trata-se de olhar o interior da constituição do Estado e observar até mesmo o quanto de propagandístico e ideológico havia na historiografia, que surge concomitantemente e reforçando a criação do Estado de Israel. Ao mesmo tempo, e de maneira contraditória, pela significação que abarca, pelo caráter de causa e justificativa humana máxima para a obtenção de terras, de um lar, o Holocausto foi pouco abordado, como se o questionamento visasse mais exatamente o sionismo e a maneira como este se apropria do Holocausto para reforçar a existência do Estado, deixando de lado muitas vezes a compreensão das questões que estão no embricamento trágico de dois destinos: o judeu e o palestino.

Uma tentativa de compreensão abarcando os dois campos pode ser vista em Kedma, filme de Amós Gitai, de 2002, em que o cineasta faz se encontrarem, nesse mesmo momento de 1948, os refugiados judeus que chegavam dos campos de concentração e dos campos de pessoas deslocadas ${ }^{15}$ - ainda alquebrados e desesperançados - e que já eram transformados em soldados, e os palestinos que tinham que deixar suas terras. Na cena em que chegam os refugiados europeus, Gitai faz, num mesmo plano longo em panorâmica, cruzar diante deles uma família de palestinos que se retira, desalojada pelo 
grupo e pelos soldados que ali estão. Aproveitando a profundidade do campo visual e sem picotar a cena pela montagem, num único plano a câmera de Gitai junta no mesmo enquadramento todos os protagonistas daquela história: sobreviventes judeus, jovens da Haganá, palestinos e os soldados ingleses que ocupavam como mandatários aquele território. Não há exatamente violência, não há expulsão. Há algo como que inevitável, incontornável, injusto, confuso que desfila diante do espectador, como a tentar captar nessa indefinição as linhas desse acontecimento e desse momento, ao mesmo tempo dilacerante e fundador. E cada um dos protagonistas - judeu e palestino - faz seu discurso desesperado. O palestino que deixa a sua terra, e o judeu que deixara um conflito e, mal chegando a Israel, já se vê parte de outro.

É preciso entender, lembra Gitai, em primeiro lugar que há uma tragédia dupla, a dos judeus e as dos palestinos que se desenvolveu no século XX e que elas são cruelmente entremeadas e não simétricas. ${ }^{16}$

\section{OUTRO SIONISMO? UM PÓS-SIONISMO?}

Dessa forma, o que se evidencia nesses trabalhos é o surgimento de um "pós-sionismo" que, se não abdica inteiramente do sionismo, já não aceita mais se submeter aos mesmos compromissos e a sacrifícios como servir o exército constantemente, e, sobretudo servir o exército perseguindo palestinos em territórios ocupados. Shlomo Sand, autor de um livro sobre os intelectuais em Israel, de 2006, e do recente "A invenção do povo judeu" "17, onde questiona justamente as ideias nacionalistas, observa, parafraseando Karl W. Deutsh, que "uma nação é um grupo de gente unida por um equivoco comum sobre a sua origem e uma hostilidade coletiva pelos seus vizinhos: ${ }^{18}$

[...] A maior parte dos novos historiadores não se consideram nem mesmo como sionistas, na medida em que o Estado, aos seus olhos, não poderá continuar duravelmente um Estado judeu: será necessário que ele se torne um Estado de todos os seus cidadãos, judeus como árabes judeus como muçulmanos e cristãos. Isso é o que significa exatamente "pós-sionismo": normalizações do exterior e do interior que caminham juntas. ${ }^{19}$

Sand não representa nessa afirmação toda a gama de opiniões sobre como chegar à paz e às novas configurações do sionismo, mas o certo é que 
todas passam necessariamente pelo reconhecimento do Outro, que é o palestino, e pelo reconhecimento não só de sua existência, mas do direito à memória de sua tragédia. É esse o sentido político das várias histórias que vêm sendo escritas nos últimos 20 anos em Israel e dos vários filmes realizados nesse mesmo sentido. Se não representam um campo majoritário, têm servido para descentrá-lo, questionando na historiografia tradicional de Israel o caráter afirmativo, certamente defensivo, da existência do Estado, deslocando seu sentido para a existência do Estado, sim, mas sob outras condições, condições que reconhecem e integram o Outro que é também parte constitutiva dessa história. Como chama a atenção Yehuda Lancry, antigo embaixador israelense na França e nas Nações Unidas:

Nessa querela de novos e velhos [historiadores] é também o ethos de Israel e sua identidade em gestação que estão em causa. Forjado longamente sob a ameaça de aniquilação, o ser israelense deve necessariamente abrir a sua narrativa e seus mitos fundadores às narrativas do Outro, palestino e árabe. É nesse cruzamento de narrativas, sua interpenetração, seus choques e catarses, substâncias indispensáveis do reconhecimento mútuo contraído em Oslo, ${ }^{20}$ que deve se inscrever a palavra de paz e de reconciliação. ${ }^{21}$

Do ponto de vista da recepção dessas várias obras em Israel, vale observar que todos os autores são israelenses, todos se graduaram em Israel, mas a maioria dos trabalhos foi realizada em doutoramentos no exterior, entre os Estados Unidos e a Inglaterra, lugares onde foram inicialmente publicados, sendo que alguns dos autores continuam inéditos e outros, como Pappe, escolheram morar fora de Israel. Os livros desses historiadores, começando pelo de Benny Morris, de 1988, tiveram ampla repercussão, e como vimos pelos títulos e pelas datas, continuam a ser lançados, apaixonadamente criticados pelos outros historiadores, mas encontram entre os intelectuais pacifistas, e no jornal Haaretz, um lugar de apoio e divulgação.

A questão da responsabilidade pelo êxodo palestino, tema do livro de Benny Morris causou impacto e foi para os meios de comunicação no ano mesmo de seu lançamento, que coincidiu com o da comemoração dos 40 anos de Israel. Aliado à declaração do Estado palestino, conduziu até mesmo a mudanças nos livros didáticos israelenses, que começaram a tocar nessa e em outras questões. Entretanto, com os revezes depois do assassinato de Rabin em 1995 e da frustração com Camp David em 2000, em 2001 Ariel Sharon, então no poder, os tirou de circulação. Essa censura põe a nu, em primeiro lugar, o caráter controverso da democracia israelense, e paralelamente, a persistência 
das narrativas históricas tradicionais, reforçadas agora pelo recrudescimento do campo nacionalista, que alimentou a expansão da implantação de colônias em território ocupado, tendo na justificativa bíblica e religiosa os seus indiscutíveis argumentos.

Pelos títulos publicados em 2008 dentro e fora de Israel, a comemoração dos 60 anos de existência aprofundou a cisão entre sionismo e pós-sionismo, entre as formas de imaginar e conduzir o Estado e o lugar da paz. Do ponto de vista historiográfico, um mergulho nos mitos, nas questões da identidade e do nacionalismo. Quando Sholomo Sand se volta para a "Invenção do povo judeu", traz novas e instigantes discussões historiográficas. Ele observa, por exemplo, o quanto a escrita da história dos judeus e de Israel se subordinou à ideia - sempre necessariamente demonstrada historicamente - de uma ligação indissolúvel entre o povo e aquele território desde os tempos bíblicos. Em nome desse culto às raízes bíblicas o autor fala, entre outras, da febre arqueológica e de sua relação direta com o poder do Estado nos anos 1960, por exemplo, e como os próprios políticos se transformam em estudiosos de arqueologia, como o general Moshe Dayan, ou historiadores como o primeiro ministro Abba Eban. E quando a arqueologia desmentia as necessidades do Estado, calava-se a arqueologia!22

Muito desses questionamentos podem ser vistos no cinema israelense, e o mesmo destino de errância também pode ser visto entre os cineastas que, como os historiadores, tem produtoras e ligações fora de Israel para financiar e divulgar os filmes, uma vez que em seu próprio território os trabalhos são vistos com restrição e críticas contrárias, isso quando são vistos. Observemos um pouco desse processo.

\section{OUTRAS HISTÓRIAS NO CINEMA}

Em 1980, Amós Gitai filmou para a televisão israelense o documentário Bait (Casa), onde mostrou pela primeira vez o destino de uma casa em Jerusalém, que era originalmente de palestinos, foi apropriada pelo governo depois de 1948 e finalmente vendida em 1977. Fala, portanto, ainda em 1980, da mesma história e dos mesmos mitos que vão interessar aos 'novos historiadores': a Guerra de Independência e o êxodo palestino, de uma perspectiva da micro-história. $\mathrm{O}$ filme, como era previsível, foi censurado e teve a exibição proibida, devido ao seu conteúdo. Conforme nos lembra o diretor: "Em 1980 não se falava, não se admitia, não se imaginava que as casas que os israelenses ocupavam haviam tido uma vida anterior àquela que os judeus conheceram". ${ }^{23}$

Quando Gitai filma essa casa, o seu antigo morador, um médico de família palestina tradicional, fala de sua vida naquele lugar. Recupera diante 
do espectador a rica memória de outra vida que foi apagada e a sua supressão pelo desterro. Faz a fala reconstituir a memória - e nessa narração diante da câmera outra história se revela. A história de um povo que existia - ao contrário do que se afirmava em Israel - e de um êxodo forçado: um destino que se interrompe e dá lugar a outro. Esse novo destino surge na figura do casal de judeus argelinos que passa a viver na casa em 1956. Mais tarde, no momento da filmagem, em 1980, a casa pertence a um professor de economia que a comprou depois que o governo de Menachen Begin, em 1977, decidiu que as propriedades palestinas sob responsabilidade do governo de Israel desde 1948 fossem vendidas. O novo proprietário, diante da câmera, faz crer, ostensivamente, que desconhece todo o passado do lugar onde vive. Como se quisesse deliberadamente negar as camadas de história e conflitos de que a sua casa era não só testemunha, mas palco. Só o presente lhe dizia respeito documentava, assim, um dos principais componentes dessa história e do seu conflito: a negação do outro.

A casa filmada em Jerusalém Oeste (na região judaica da cidade) era considerada pelo governo "propriedade abandonada", num processo que vinha ocorrendo desde 1948 até a década de 1970. Segundo Gitai, desde 1948 as casas deixadas pelos palestinos haviam sido requisitadas pelo governo e até 1977 tinham sido emprestadas ou alugadas a terceiros. O governo se abstivera de vendê-las. Do ponto de vista legal, o Estado tornava-se seu proprietário até a resolução do conflito. Entretanto, depois de 1977 o governo de Begin resolve vendê-las: ${ }^{24}$ digamos que deu o conflito por terminado! A lei sobre "propriedades abandonadas" abrangia os terrenos agrícolas e as moradias. Bastava que os moradores se ausentassem por alguns dias para que seus terrenos e casas se tornassem propriedade do Estado. Era uma lei provisória que, segundo Gitai, escondia uma segunda intenção política: se um estatuto definitivo dos territórios fosse instaurado, isso obrigaria o Estado de Israel a negociar (idem). O diretor observa ainda que os impostos na região eram tão elevados que equivaliam a expulsar os palestinos, forçando-os a emigrar para a Cisjordânia onde as taxas eram menores. Tudo era feito para que os palestinos deixassem Jerusalém. Casa procura documentar um pouco de todo esse intrincado processo que era vivido pela negação da ocupação, como antecipou Gitai.

Como observou no jornal Libération o crítico Serge Daney, já então ex-diretor de redação da revista Cahiers du Cinéma:

Gitai quer que essa casa se torne ao mesmo tempo algo muito simbólico e muito concreto, que ela se torne um personagem de cinema. Acontece uma das mais lindas coisas que uma câmera pode registrar ao vivo: pessoas que olham para a mesma coisa e veem coisas diferentes. E como 
essa visão é comovente! Na casa parcialmente desmoronada, verdadeiras alucinações tomam corpo. A ideia do filme é simples, e o filme tem a força dessa ideia. Nem mais nem menos. ${ }^{25}$

É nessa riqueza de espelhamentos múltiplos sobre um único objeto que Gitai consegue fazer ver ao espectador o seu entendimento da questão, um entendimento que acolhe a contradição e a tragédia, como diz ele, a tragédia dupla dos judeus e dos palestinos, que "são cruelmente entremeadas e não simétricas".

Casa promove uma inédita arqueologia. Desencava a então oculta ocupação dentro do território de Israel (como fará Gitai também em Esther, de 1985, filmado nas antigas regiões árabes da cidade). Ocupação da casa, ocupação do território, êxodo, exílio, expulsão, apropriação, negação judaica, necessidade territorial, histórica e cultural judaica. Está tudo ali naquela casa, a que Gitai vai retomar quase 20 anos depois em Uma Casa em Jerusalém, de 1998, e em 2005 com News from Home, New from House, já que a ocupação e as tragédias duplas de palestinos e israelenses só se adensam, e não param de se reproduzir.

Ao contrário de Amos Gitai que se dedica à ficção e ao documentário, Eyal Sivan é unicamente documentarista, e como Gitai também encontra problemas na recepção de seus filmes em Israel. Sua obra é marcada pelo questionamento dos usos do passado na conformação da identidade israelense e do Estado de Israel. Entre 1991 e 1999 realizou dois filmes que interrogavam os usos da memória coletiva do Holocausto em Israel. Em 1991 filmou Izkor: Slaves of Memory (Escravos da Memória) e em 1999 The Specialist (O Especialista). No primeiro, com a participação de um intelectual de prestígio em Israel, Yeshayauh Leibowitz, o diretor examinou a comemoração escolar (do maternal ao segundo grau) de várias efemérides do calendário concentradas em Abril, que estão ligados a momentos em que se deve lembrar (Izkor) lembrar a expulsão do Egito nos dias de Páscoa, lembrar do Holocausto e da Guerra de Independência. Segundo Yael Munk, professora da Universidade Aberta de Israel:

De acordo com Leibowitz (e o cineasta), esta condensação de celebrações não tem outro significado senão o de explorar a memória histórica da opressão judaica e apropriar-se dela para a justificação da política israelense atual. Essa falácia permite uma leitura da história segundo a qual a submissão à autoridade do Estado é apresentada como a essência do humanismo e do Judaísmo. ${ }^{26}$ 
É fácil imaginar a controvérsia que a recepção do filme causou. Críticos em Israel chegaram a dizer que o filme procurava agradar a esquerda europeia. Com O Especialista ele retoma o julgamento Adolf Eichman ${ }^{27}$ a partir da leitura de Eichman em Jerusalém: um relato sobre a banalidade do mal de Hanna Arentd e segundo Yael Munk:

Sivan reeditou as imagens oficiais do julgamento a fim de "desconstruir a dicotomia entre acusado e acusador sugerindo que os incriminadores israelenses e seus herdeiros contemporâneos poderiam ser culpados de algumas das acusações feitas contra o réu..$^{28}$

Sivan retomava as duras críticas de Hanna Arendt que em seu livro de 1963 apontava o uso político do julgamento de Eichman como um espetáculo político com vistas à formação de uma consciência judaica que parte significativa da população israelense, composta por judeus orientais, desconhecia. Essa consciência deveria estar centrada no Holocausto e no seu significado para a existência de Israel. Por seu conteúdo, o livro de Arendt, lançado em 1963, só foi editado em Israel em 2000, um ano depois do lançamento do também muito criticado filme - que uma vez mais interroga o uso da memória do Holocausto na formação da consciência política israelense. ${ }^{29}$

Em Jaffa, a mecânica da laranja ${ }^{30} \mathrm{o}$ alvo é o sionismo e a construção do Estado de Israel. A escolha do título, evocando o filme de Stanley Kubrick, não é gratuito, pois é de violência que se trata aqui, como se poderá ver. O documentário é expositivo, organizado a partir de vasto material de arquivo como fotos, filmes, propagandas, rótulos e imagens várias que são comentadas por historiadores, pesquisadores de imagens, pintores, assim como agricultores envolvidos com o cultivo de laranjas, sempre palestinos e israelenses acompanhados de músicas das épocas enfocadas. Partindo desse vários testemunhos que muitas vezes contrapõem diferentes pontos de vista, Sivan reconstrói a história de Jaffa, um importante porto palestino, e de suas perfumadas laranjas, que eram dali exportadas para a Inglaterra ${ }^{31}$, lembrando não só o colonialismo de que são parte, mas também o orientalismo que recobre a imagem desse produto e desses lugares, vendidos como 'exóticos' desde o século XIX. Ao contrário disso, a Israel sionista vai se constituir sobre a imagem da modernidade e dos esforços que levam ao desértico Oriente a fertilidade e o esplendor de um passado longínquo. Isso significava dizer que até o início do século XX, quando começa o retorno de populações judaicas, as terras eram virgens, ou que ninguém se ocupava convenientemente delas. Assim, as laranjas Jaffa são o resultado, a prova do sucesso desse árduo e necessário trabalho. Corroborando essa imagem de uma terra que clamava pelo 
seu resgate, desde 1840, um ano depois da invenção da fotografia, fotógrafos europeus enquadravam paisagens supostamente bíblicas como desérticas, mostrando assim a necessidade de conquista. As imagens produzidas pelo sionismo décadas mais tarde, vão projetar a ideia dessa arrancada: nos filmes, as propagandas se constroem como num western com tratores revolvendo a terra, muitas imagens em contra-plongée ${ }^{32}$, imagens próximas também à retórica dos filmes soviéticos, caros aos sionistas trabalhistas, como aponta, no filme, um historiador palestino.

No entanto, como o filme vai mostrar, o cultivo das laranjas era anterior à instalação do Estado judeu e contou com a colaboração de judeus, muçulmanos e cristãos que conviveram na atividade, não sem conflitos, mas chamando a atenção para uma cooperação que foi possível, e até mesmo um reconhecimento mútuo que deixa de existir a partir de 1948. E como lembra um agricultor palestino, "toda a Palestina exportava laranjas com o nome de Jaffa. E hoje não há mais nenhuma laranja em Jaffa". ${ }^{33}$

A instalação do Estado judeu em 1948 coloca um ponto final na convivência de que falam israelenses e palestinos. Apenas $5 \%$ dos palestinos ficam em suas terras. Os laranjais tornam-se propriedade do Estado. Um antigo proprietário palestino torna-se empregado nas suas próprias terras, agora apropriadas por Israel, assim como as laranjas Jaffa, que se tornam o emblema do novo Estado ensolarado e seu principal produto de exportação. Nas propagandas sionistas podem-se ver homens e, sobretudo mulheres jovens que colhem laranjas usando shorts e mostrando corpos esbeltos, enquanto mulheres cobertas da cabeça aos pés - imagem de palestinas - carregam fardos. A ideia da modernidade contra o atraso é reforçada e viaja mundo afora junto com as laranjas Jaffa. E a história da tragédia palestina, da 'Naqba', do êxodo e de sua própria existência naquelas mesmas terras é apagada. Pode-se dizer, varrida. Essa história, essa convivência possível foi enterrada. O reconhecimento da existência do outro, negada.

$\mathrm{Na}$ 'mecânica da laranja', como se vê, houve muita violência, uma violência que se construiu pela usurpação, mas, sobretudo pelo apagamento da existência do outro, pela sua imagem como negativa, atrasada. E é isso que o filme capta, ainda que se possa criticar certo maniqueísmo quanto à apresentação desprovida de conflitos entre os palestinos, contra a violência simbólica ou concreta, sempre unívoca entre os israelenses.

Para muitos a desconstrução feita por Sivan pode soar incômoda, até anti-sionista como ele e outros historiadores já foram acusados, e por isso se exilaram de Israel. No entanto, preferem enfrentar o incômodo a negar o outro como vem ocorrendo nos discursos tradicionais. Quando Gitai, Sivan e os 'novos historiadores' recusam os mitos estabelecidos e aprofundam seu questionamento sobre a história, é com vistas a um futuro distinto, a outra história capaz de incluir a paz. 
Por outro lado, haveria ainda o que dizer de filmes comerciais que vêm sendo produzidos por Israel nos últimos anos, e mesmo de filmes palestinos como Paradise Now de Hany Abu-Assad de 2005. Ali se fala dos jovens que se preparam com ansiedade para se tornar homens bomba oferecendo suas vidas em ataque suicida a Israel. Outros filmes simplificam e banalizam a questão israelo-palestina, como Bubble, de Eytan Fox, 2006, comédia dramática israelense sobre um casal gay formado por um israelense e um palestino, que revivem na Tel Aviv atual e pós-moderna a tragédia de Romeu e Julieta. Banalização, boa consciência, os amantes são mortos pela incompreensão de sua tragédia individual - a homossexualidade - e política. Utilização mais do que duvidosa do conflito, filmes como esses servem-se de enredos oportunistas, chamando a atenção para a apropriação comercial do confronto.

Lemon Tree de Eran Ricklis, de 2008, se baseia numa história real sobre viúva palestina que luta pela manutenção de seu centenário limoeiro contra a decisão do serviço secreto israelense que julga a árvore uma ameaça. Banalizações e boas intenções dão forma simplista a personagens de palestinos e israelenses e não avançam na compreensão da complexidade de questões envolvidas. Uma Juventude como Nenhuma Outra, de Vardit Bilu e Dalia Hager, de 2005, ao contrário, mostra com sensibilidade a vida cotidiana de duas chaialot (soldadas) que se apaixonam, se frustam e brigam como quaisquer jovens de 18 anos, mas ao mesmo tempo têm como ofício controlar e, a contragosto, reprimir senhoras palestinas. Beaufort de Joseph Cedar, premiado no Festival de Berlim de 2007, fala da ocupação militar no Líbano, e da recusa em lutar nos territórios ocupados.

Haveria certamente muito mais a dizer sobre a nova história de Israel a partir da observação tanto das mudanças contemporâneas da historiografia como da produção cinematográfica. Como procuramos mostrar, não houve nesses processos a submissão de um campo ao outro, mas diálogos, diferenças de enfoque, complementação.

\section{NOTAS}

1 HARTOG, François. “Tempo e História: Como escrever a História da França hoje?”. História Social, n. 3, IFCH-UNICAMP, Campinas, p. 127-154, 1996. (Artigo original publicado nos Annales ESC, n. 6, p. 1219-1236, 1995).

2 SCHIAVINATTO, Iara Lis. Comentário VIII: Sobre o campo de visibilidade: entre o passado e o futuro. Anais do Museu Paulista, História e Cultura Material, v. 15, n. 2, São Paulo, jul./ dec. 2007. Disponível em: <http://www.scielo.br/scielo.php?script=sci_arttext\&pid=S010147142007000200010\&lng=en\&nrm=iso>. Acesso em: 12 jul. 2012.

3 VIDAL, Dominique; BOUSSOIS, Sebastien. Comment Israel Expulsa les Palestiniens (1947-1949). Paris: Atelier, 2007. 
4 Ibidem, p. 33.

5 MORRIS, Benny. The Birth of the Palestinian Refugee Problem: 1947-1949. Cambridge: Cambridge University Press, 1988. O livro é o resultado de uma tese de doutorado na Cambridge University.

6 PAPPE, Ilan. "La critique post-sioniste en Israel”. La Revue d'études palestiniennes, n. 12, été 1997.

7 VIDAL; BOUSSOIS, op. cit., p. 33.

8 PAPPE, op. cit.

9 VIDAL, Dominique; ALGAZY, Joseph. Le péché originel d'Israel. Paris: Atelier/Les Éditions Ouvrières, 2002.

${ }^{10}$ Os livros mais importantes são: FLAPAN, Simcha. The Birth of Israel: Miths and Realities. New York, 1987; SEGEV, Tom. 1949 The First Israelis. New York e Londres: Free Press Macmillan, 1986; SHLAIM, Avi. Collusion Across the Jordan: King Abdallah, the Zionist Mouvement and the Partition of Palestine. Oxford: Clarendon Press, 1988; PAPPE, Ilan. Britain and the Arab-Israeli Conflict, 1948-1951. Londres: I.B. Taurus, 1988; PAPPE, Ilan. Le Nettoyage ethnique de la Palestine. Paris: Fayard, 2008; MORRIS, Benny. The Birth of the Palestinian Refugee Problem Revisited. Cambridge: Cambridge University Press. 2004; MORRIS, Benny. 1948 and after: Israel and the Palestinians.Oxford: Claremon Press, $1990 \mathrm{e}$ o mais recente de SAND, Shlomo. Comment Le Peuple Juif Fut Inventé. Paris, Fayard, 2008. Traduzido para o português como A Invenção do Povo Judeu. São Paulo: Benvirá, 2011.

${ }^{11}$ Parte baseado em fatos reais, parte em ficção, A Sombra de Um Gigante apresenta uma dramatização da luta de Israel entre 1947-48 pela independência na forma de um melodrama encabeçado por um elenco de estrelas da época que incluía Kirk Douglas, Senta Berger e Angie Dickinson, além de Yul Brynner, John Wayne e Frank Sinatra em papéis coadjuvantes. Após uma carreira brilhante no exército norte-americano um herói da $2^{\mathrm{a}}$ Guerra Mundial, o judeu americano Mickey Marcus (Douglas) é chamado ao novo Estado de Israel para ajudar a organizar um exército capaz de enfrentar seus inimigos árabes. Contra a vontade de sua esposa (Dickinson), Mickey parte na perigosa jornada e começa a transformar um confuso exército clandestino em uma máquina de combate de primeira classe. Mas à medida que a ameaça de guerra se aproxima, Mickey também precisa enfrentar sua crescente atração pela bela ativista Magda Simon (Berger).

${ }^{12}$ FLAPAN, Simcha. The Birth of Israel. Myths and Realities. Londres/Sydney: Croom Helm, 1987.

${ }^{13}$ Ibidem.

${ }^{14}$ BOUSSOIS, Sébastien. "Postface: De la nouvelle histoire au post-sionisme". VIDAL; BOUSSOIS, op. cit.

${ }^{15}$ Campos de Pessoas deslocadas são formados depois da $2^{\mathrm{a}}$. Guerra, sobretudo pelos sobreviventes dos campos de concentração, sem possibilidades de retorno à sua terra de origem.

${ }^{16}$ TOUBIANA, Serge. Amos Gitai: Percursos, Exílios e Territórios. São Paulo: Cosac \& Naif, Mostra Internacional de Cinema de São Paulo, 2004.

${ }^{17}$ SAND, Shlomo. A Invenção do Povo Judeu. São Paulo: Benvirá, 2011.

${ }^{18}$ Ibidem. 
${ }^{19}$ Sand que é professor de História Contemporânea na Universidade de Tel Aviv, é autor também de "Le XX siècle à l'écran".Paris:Fayard, 2004, livro instigante sobre a construção da historia do século XX através de filmes, com ênfase no encontro de aspectos políticos que nos interessam diretamente como "A estetização da miséria? Lutas de classe e crises econômicas como objetos fotogênicos” entre outros. VIDAL; BOUSSOIS, op. cit., p. 222.

${ }^{20}$ Lancry se refere aos Acordos de paz de 1993 contraídos entre Arafat e Rabin.

${ }^{21}$ VIDAL; BOUSSOIS, op. cit., p. 15.

${ }^{22}$ SAND, op. cit., p. 195.

${ }^{23}$ TOUBIANA, op. cit., p. 118.

${ }^{24}$ TOUBIANA, op. cit., p. 119.

${ }^{25}$ Libération 01 mar. 1982, apud TOUBIANA, ibidem, p. 241.

${ }^{26}$ MUNK, Yael. The Dissidents: Avi Mograbi, Amos Gitai and Eyal Sivan 1 dec. 2009. Disponível em: $<$ http://www.eyalsivan.info/index.php?p=written\&id=11 $>$ Acesso em: 18 jul. 2012.

${ }^{27}$ Eichman, o criminoso nazista que foi raptado pelos israelenses na Argentina em 1960, julgado em 1962 quando foi declarado culpado e enforcado.

${ }^{28}$ Ibidem.

${ }^{29}$ Não consegui assistir a esses filmes. Me baseei em material bibliográfico sobre o diretor de forma a situar a sua produção.

${ }^{30}$ Disponível em: <http://www.youtube.com/watch?v=4Cgb-VbL7dA>. Acesso em: 18 jul. 2012.

${ }^{31}$ Os ingleses ocupam a Palestina a partir de 1917.

${ }^{32}$ Imagens focalizadas de baixo para cima o que tende a engrandecer o objeto enfocado. No caso, os tratores.

${ }^{33}$ Jaffa transforma-se depois de 1948 em Iaffo, um bairro que faz parte de Tel Aviv.

Artigo recebido em junho de 2012. Aceito em agosto de 2012. 